\title{
Impact of Square Fuel Assemblies Arrangement on Fluid Flow and Heat Transfer Enhancement inside Water Filled Enclosures
}

\author{
Karim RAGUI ${ }^{1, *}$, Abdelkader BOUTRA $^{1,2}$ and Youb Khaled BENKAHLA ${ }^{1}$ \\ ${ }^{1}$ Laboratory of Transport Phenomena, USTHB, Algiers, Algeria. \\ ${ }^{2}$ Preparatory School of Science and Technology, Algiers, Algeria. \\ *ragui-karim@live.fr, aeknad@yahoo.fr, youbenkahla@yahoo.fr
}

\begin{abstract}
Keywords: Computational fluid mechanics/ cold enclosure/ square sources/ rectangular
\end{abstract} disposition/ lozenge disposition/ finite volume method.

\begin{abstract}
Through this paper, the hydrodynamic and thermal characteristics of a Newtonian fluid within a square cold enclosure containing four inner heaters, arranged in different manners, are numerically investigated. To do so, a developed computer code based on the finite volume method and the SIMPLER algorithm is used. The validity of the latter was ascertained after the comparison between the obtained results and the experimental and numerical ones already available in the literature. To make clear the effect of pertinent parameters such the Rayleigh number and the distance between these heaters, the phenomenon was reported by means of Streamlines, Isotherm plots, velocity and temperature profiles, with a special attention to the local and average Nusselt number evolution. As shown in the latter, taking into account the heaters' arrangement into the enclosure leads to a significant improvement of the overall transfer. Consequently, powerful correlations predicting the heat transfer ratio into the cold square as a function of the heaters' disposition are proposed which predict within $\pm 1 \%$ the numerical results.
\end{abstract}

\section{Introduction}

Natural heat transfer convection of Newtonian fluids such air and water in enclosures has received considerable attention over the last four decades by many researchers, both experimentally and numerically [1-5]. This interest stems from its importance and its wide range of applications such as heat exchangers, home ventilation, electronic cooling devices, solar power collectors, and nuclear reactor core, to name but a few.

As shown in the literature, the natural convection in differentially heated cavities with adiabatic partition or heat generating body becomes a classical research problem extensively studied by many authors [6-13] in the main idea that these kinds of obstacles would change the flow and the heat transfer characteristics by many ways.

Bouafia and Daube [14] examined numerically natural convection inside a cavity filled with air under large temperature gradient. The flows were generated by a heated solid body located near to the bottom wall in a rectangular cavity with cold side walls. However, their interest was in the first transitions which occurred when the Rayleigh number was increased for flows in cavities of different aspect ratios.

Ha and Jung [15] studied natural convection within a differentially heated cubic enclosure including a cubic heater. Under these conditions, they examined the effects of Rayleigh and Prandtl numbers on heat transfer enhancement. The effect of the ratio between the temperature difference across the enclosure and that one induced by the hot centered source on the mean Nusselt number of the active walls was widely inspected. They concluded that the heat transfer is an increasing function of Rayleigh number when both; the fluid and temperature fields are strongly dependent on the hot block size.

Dagtekin and Oztop [16] investigated natural convection into an enclosure containing two rectangular heaters, of different heights, mounted on the bottom wall. Both the left and the top wall were maintained at a uniform temperature lower than that imposed on the two partitions while the 
right wall was assumed to be insulated. Summarizing their predictions, the mean Nusselt number was found as an increasing function of the height and the spacing between the two heaters.

Ampofo [17] conducted an experimental study of turbulent natural convection of air into a Nonpartitioned and partitioned cavity, with differentially heated vertical and conducting horizontal walls. Five horizontal partitions of high thermal conductivity were utilized in the aim to provide highly accurate turbulent convection data, which can provide further insight into the fluid flow and heat transfer of natural convection and also be useful for the validation of computational fluid dynamics codes.

Even though there have been these numerous investigations conducted on natural convection in partitioned enclosures, under many configurations and boundary conditions, relatively few studies were documented in the case of cavities containing several blocks (three partitions and more), [1820].

As such, a comprehensive numerical study on laminar natural convection into a square cold cavity having four square heaters mounted in rectangular or lozenge disposition is developed through this paper. The effect of the heaters' arrangement on the dynamic and thermal fields is widely investigated, to come out at the end with global correlations predicting the square mean transfer. The proposed dispositions of these sources are very important in many industrial applications, especially in cooling fuel assemblies, and in particulate exchangers used in the Refining and Petrochemical industry.

\section{Problem Statement and Mathematical Formulation}

The problem under investigation is a laminar, two dimensional natural heat transfer convection in a square cold cavity, with four square heaters of a width equal to $10 \%$ the cavity' length. The physical problem with its boundary conditions is shown in Fig. 1. Three cases are taken into consideration: Case 01 in which the square enclosure of Fig. 1(a) filled with convective fluid, having a centered square heater formed by the square bodies. Case 02 as shown Fig. 1(b), is a

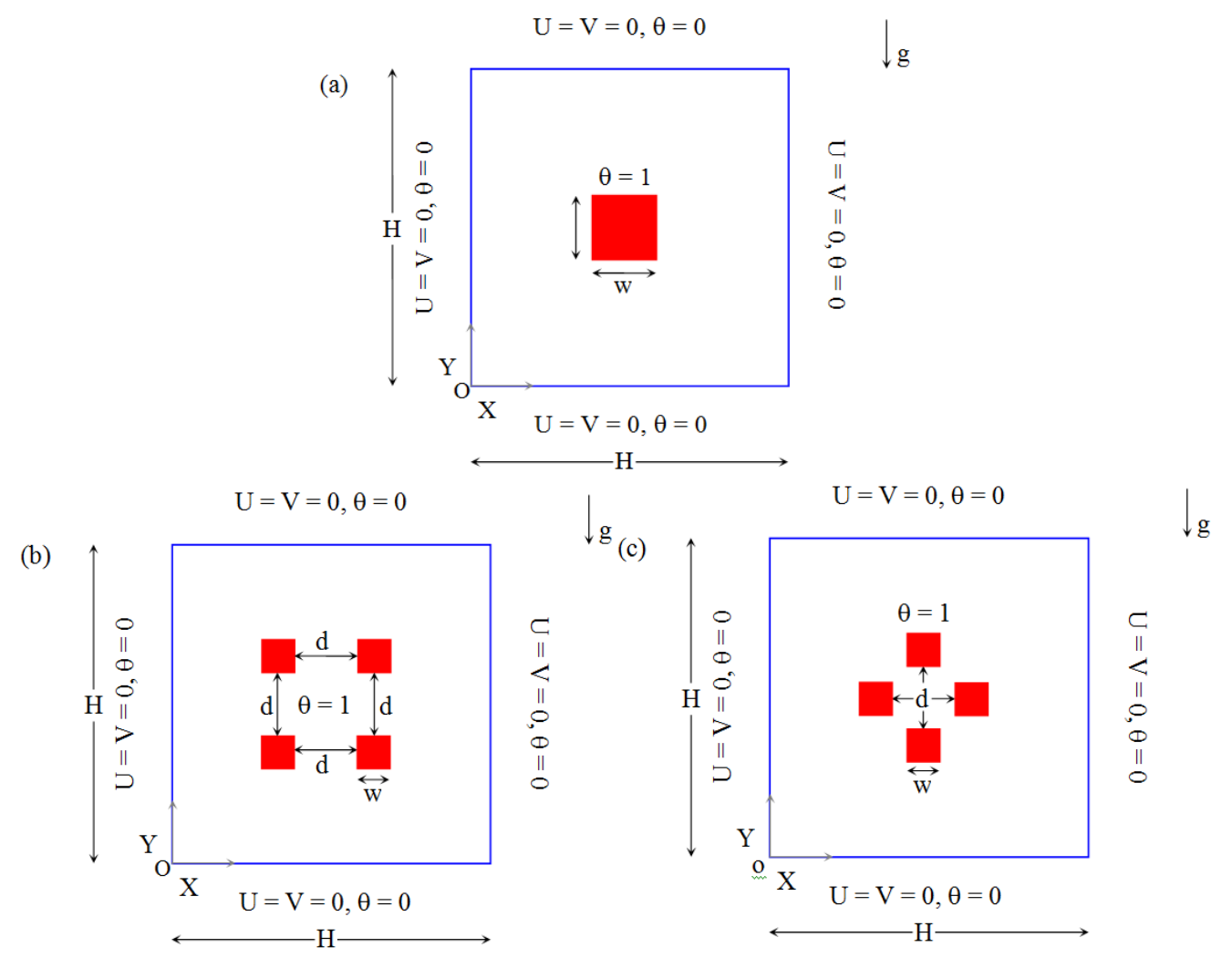

Fig. 1 Simulation domain with its boundary conditions. Case 1 (a), Case 2 (b), Case 3 (c). 
square enclosure with four square heaters mounted inside in a rectangular arrangement. Case 03, is the same cavity shown in Fig. 1(b) with four heaters; mounted in a lozenge disposition (Fig. 1(c)). The remaining area is completely filled with the convective fluid, its thermo-physical properties are assumed to be constant, except the density which varies according to the Boussinesq approximation [21].

The dimensionless conservation equations describing the transport phenomenon inside the cold square can be written as:

$$
\begin{aligned}
& \frac{\partial \mathrm{U}}{\partial \mathrm{X}}+\frac{\partial \mathrm{V}}{\partial \mathrm{Y}}=0 \\
& \mathrm{U} \frac{\partial \mathrm{U}}{\partial \mathrm{X}}+\mathrm{V} \frac{\partial \mathrm{U}}{\partial \mathrm{Y}}=-\frac{\partial \mathrm{P}}{\partial \mathrm{X}}+\frac{1}{\mathrm{Gr}^{1 / 2}}\left\{\frac{\partial}{\partial \mathrm{X}}\left(2 \mu \frac{\partial \mathrm{U}}{\partial \mathrm{X}}\right)+\frac{\partial}{\partial \mathrm{Y}}\left[\mu\left(\frac{\partial \mathrm{U}}{\partial \mathrm{Y}}+\frac{\partial \mathrm{V}}{\partial \mathrm{X}}\right)\right]\right\} \\
& \mathrm{U} \frac{\partial \mathrm{V}}{\partial \mathrm{X}}+\mathrm{V} \frac{\partial \mathrm{V}}{\partial \mathrm{Y}}=-\frac{\partial \mathrm{P}}{\partial \mathrm{Y}}+\frac{1}{\mathrm{Gr}^{1 / 2}}\left\{\frac{\partial}{\partial \mathrm{X}}\left[\mu\left(\frac{\partial \mathrm{U}}{\partial \mathrm{Y}}+\frac{\partial \mathrm{V}}{\partial \mathrm{X}}\right)\right]+\frac{\partial}{\partial \mathrm{Y}}\left(2 \mu \frac{\partial \mathrm{V}}{\partial \mathrm{Y}}\right)\right\}+\theta \\
& \mathrm{U} \frac{\partial \theta}{\partial \mathrm{X}}+\mathrm{V} \frac{\partial \theta}{\partial \mathrm{Y}}=\frac{1}{\operatorname{Pr}(\mathrm{Gr})^{1 / 2}}\left[\frac{\partial^{2} \theta}{\partial \mathrm{X}^{2}}+\frac{\partial^{2} \theta}{\partial \mathrm{Y}^{2}}\right]
\end{aligned}
$$

The above equations were normalized using the following dimensionless parameters:

$$
\mathrm{X}=\frac{\mathrm{x}}{\mathrm{H}} ; \mathrm{Y}=\frac{\mathrm{y}}{\mathrm{H}} ; \mathrm{U}=\frac{\mathrm{u}}{(\mathrm{g} \beta \Delta \mathrm{TH})^{1 / 2}} ; \mathrm{V}=\frac{\mathrm{v}}{(\mathrm{g} \beta \Delta \mathrm{TH})^{1 / 2}} ; \mathrm{P}=\frac{\mathrm{p}}{\rho(\mathrm{g} \beta \Delta \mathrm{TH})} ; \theta=\frac{\mathrm{T}-\mathrm{T}_{\mathrm{c}}}{\mathrm{T}_{\mathrm{h}}-\mathrm{T}_{\mathrm{c}}}
$$

where $\beta$ is the fluid thermal expansion coefficient, $\rho$ is the fluid density, $g$ is the acceleration due to gravity, $P$ is the dimensionless pressure, $U$ and $V$ are the dimensionless horizontal and vertical velocity components along $\mathrm{X}$ - and $\mathrm{Y}$-axes, respectively.

The heat transfer across the cavity walls can be quantified using a wall surface averaged Nusselt number based on the cavity length scale $(\mathrm{H})$ which is given as:

$$
\begin{aligned}
& \left|\overline{\mathrm{Nu}}_{\text {left wall }}\right|=\left|\overline{\mathrm{Nu}}_{\text {right wall }}\right|=\left.\int_{0}^{1}\left(\frac{\partial \theta}{\partial \mathrm{X}}\right)\right|_{\text {wall }} \mathrm{dY} \\
& \left|\overline{\mathrm{Nu}}_{\text {upper wall }}\right|=\left|\overline{\mathrm{Nu}}_{\text {bottomwall }}\right|=\left.\int_{0}^{1}\left(\frac{\partial \theta}{\partial \mathrm{Y}}\right)\right|_{\text {wall }} \mathrm{dX}
\end{aligned}
$$

\section{Numerical Procedure and Code Validation}

The governing equations are discretized in space using the finite volume method given by Patankar [22]. The convection-diffusion terms were treated with a Power Law scheme. The resulting algebraic equations with its associated boundary conditions are then solved using the line by line method. As the momentum equation is formulated in terms of the primitive variables $(\mathrm{U}, \mathrm{V}$ and $\mathrm{P})$, the iterative procedure includes a pressure correction calculation method, namely SIMPLER, to solve the pressure-velocity coupling. Noted that the convergence criterion for the temperature, pressure, and velocity is given as:

$$
\frac{\sum_{j=1}^{m} \sum_{i=1}^{n}\left|\phi_{i, j}^{\xi+1}-\phi_{i, j}^{\xi}\right|}{\sum_{j=1}^{m} \sum_{i=1}^{n}\left|\phi_{i, j}^{\xi+1}\right|} \leq 10^{-6}
$$


when both $\mathrm{m}$ and $\mathrm{n}$ are the numbers of grid points in $\mathrm{X}$ - and $\mathrm{Y}$-directions, respectively. $\phi$ is any of the computed field variables, and $\xi$ is the iteration number.

The performance of the using code in the natural convection problem is established by comparing predictions with other numerical results and experimental data, and by verifying the grid independence of the present results.

First, the present results are consistent with previous computations, namely those of Turan et al. [23], which deal with natural convection inside a square cavity at various Rayleigh and Prandtl numbers. By taking into account the same hypotheses, Fig. 2 illustrates the V-velocity profiles along a horizontal mid-section of the cavity, and the average Nusselt number evaluated at the hot wall. As we can see, the present results and those of Turan et al. are in excellent agreement with a maximum discrepancy of about $1.8 \%$.
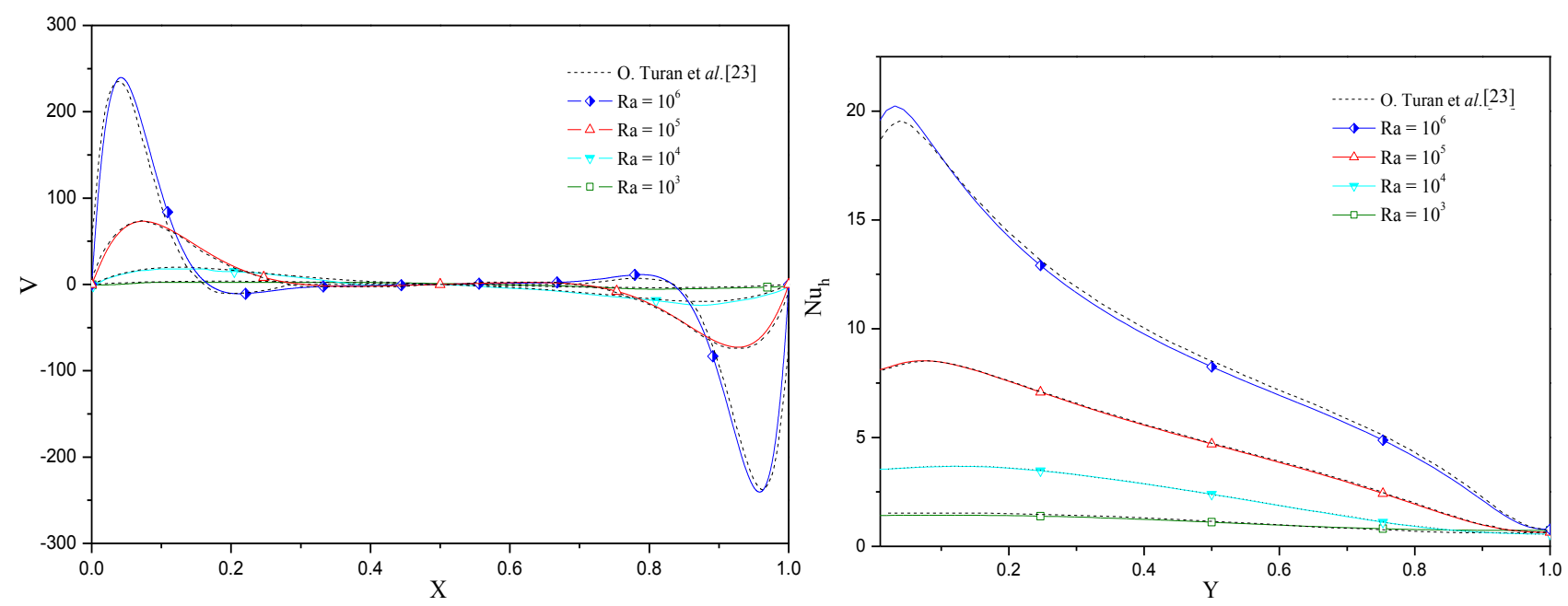

Fig. 2 Vertical velocity profiles along the horizontal mid-plane (a) and Nusselt number evaluated at the hot wall (b) for various Rayleigh numbers, $\operatorname{Pr}=7$.

To check the numerical code validity with experimental data, those obtained by Calcagni et al. [24] for various values of Rayleigh number have been selected. The physical dimensions of the air cavity used by Calcagni et al. are $0.05 \mathrm{~m}$ along the $\mathrm{X}$-axis and $\mathrm{Y}$-axis, and $0.42 \mathrm{~m}$ along the $\mathrm{z}$ axis which is large enough to justify neglecting the z-direction effects, then, the air enclosure may considered as a two-dimensional square cavity. Fig. 3 shows the comparison between the experimental data and both the numerical Kuznetsov and Sheremet validation [25] and present predictions in terms of temperature contours. As we can see, the numerical results present enough qualitative concordance with the experimental data and great agreement with the numerical Kuznetsov and Sheremet validation.

In order to determine a proper grid for the numerical simulations, a grid independence study is conducted for the natural convection heat transfer into the square partitioned cavity as shown in Fig. 1(a). Several mesh distributions ranging from $161^{2}$ to $221^{2}$ were tested. The mean Nusselt number of the cold square for the above uniform grids is presented in Fig. 4. It is observed that a $181^{2}$ uniform grid is adequate for a grid independent solution. However, a fine structured mesh of $201^{2}$ will be used to avoid round-off error for all other calculations in this investigation.

\section{Results and Discussion}

For the studied cases, the predicted (hydrodynamic and thermal) field variables are presented in terms of streamlines, isotherms, $\mathrm{V}$ velocity profiles, $\theta$ profiles and both local and average Nusselt numbers. 

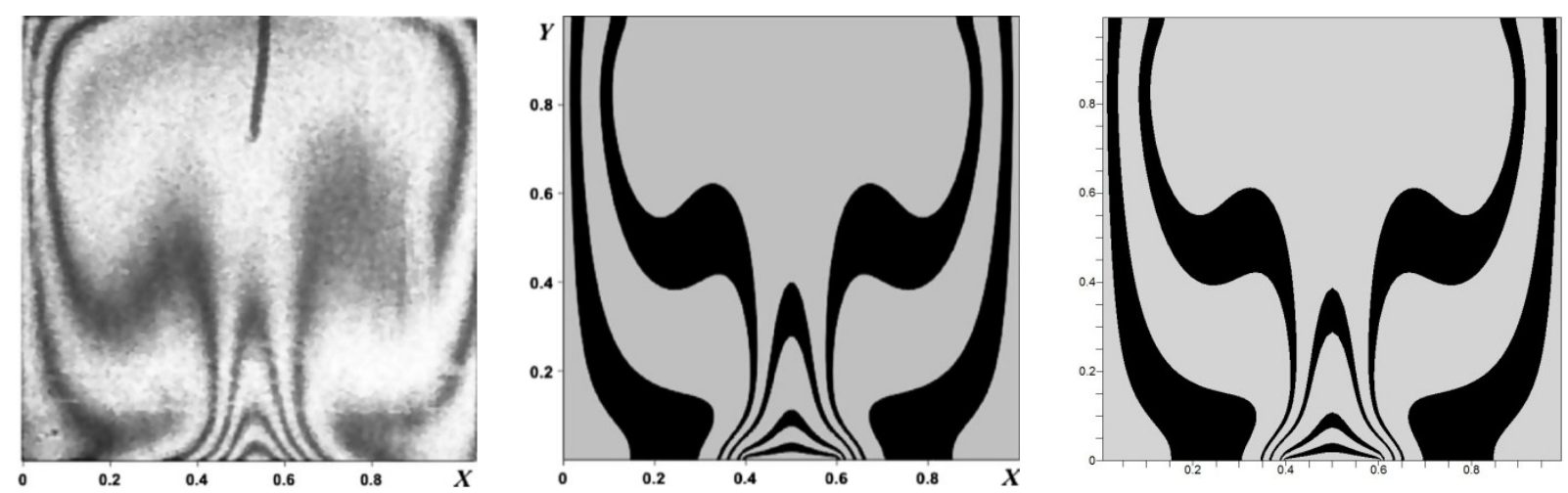

\section{$\left(\mathrm{Ra}=1.89910^{5}, \varepsilon=1 / 5\right)$}
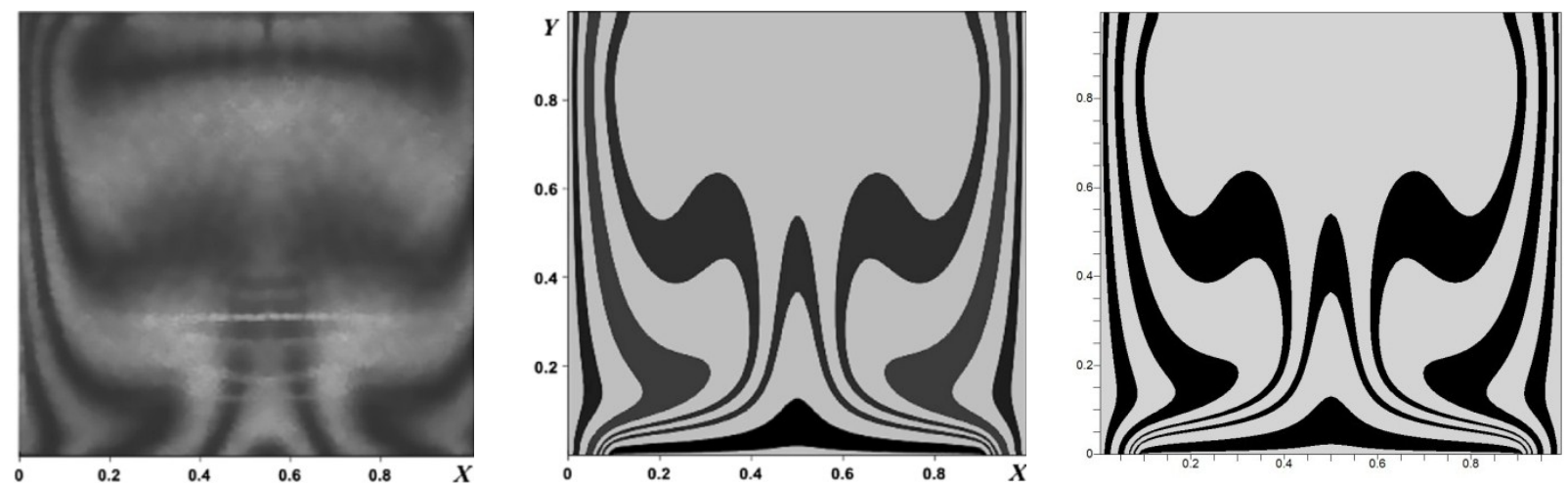

$$
\left(\mathrm{Ra}=1.42510^{5}, \varepsilon=4 / 5\right)
$$

Calcagni et al. [24]

Kuznetsov and Sheremet [25]

Present validation

Fig. 3 Comparison of temperature contours at various values of the

Rayleigh number and the source' length

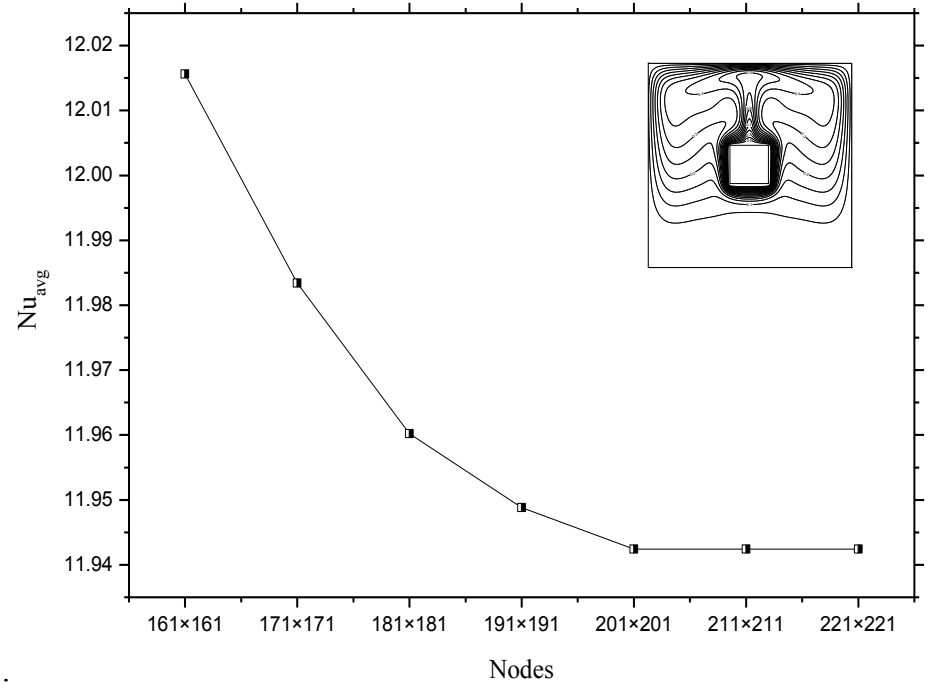

Fig. 4 Mean Nusselt number of the cold square for various uniform grids, $\operatorname{Ra}=10^{6}, \operatorname{Pr}=7$.

\section{The Blockage' Central Placement}

Start our investigation with a classic case of a heated square block mounted in the center of a cold enclosure completely filled with a Newtonian fluid. For each value of the Rayleigh number, the predicted streamlines and Isotherm plots are shown in Fig. 5.

For lower Rayleigh numbers, i.e., conduction dominant heat transfer regime, streamlines show two symmetrical counter-rotating eddies established in the left and the right sides of the heater. By increasing the Rayleigh number, the streamlines become more packed adjacent to the side walls 
when the eyes of the counter-rotating vortices move upwards, indicating more densely packed of streamlines in the top portion of the enclosure compared to its bottom. As the Rayleigh number reaches $10^{6}$, the convection mechanism becomes more pronounced and consequently, the streamlines move upwards when the eyes of the counter-rotating meet in the middle of the top portion. However, two secondary vortices are developed along the bottom surface of the cavity, these secondary vortices are generated by the fluid that remains confined in a small region created by the two primary vortices.

Regarding the isotherms shown in Fig. 5(b), for a Rayleigh equals $10^{3}$ and $10^{4}$, they seem evenly distributed demonstrating a dominated-conduction heat transfer regime. With higher values $\left(\mathrm{Ra}>10^{4}\right)$ the natural convection effect begins to dominate and then, thin thermal boundary layers are formed around the blockage surfaces, as well as along the side walls of the cold cavity and the top one, indicating large temperature gradients along these surfaces.

The hydrodynamic and thermal behaviors of the fluid within the cold cavity are summarized in Fig. 6 by illustrating the $\mathrm{V}$-velocity and the $\theta$ profiles along the horizontal mid-plane of the cavity. The examination of the magnitude of $\mathrm{V}$ at different $\mathrm{Ra}$ confirms the results previously obtained from analysing the streamlines. The vertical velocity profiles verify the existence of clockwise and anti-clockwise circulating cells inside the enclosure. The increase of the magnitude of $\mathrm{V}$ with increasing Rayleigh value is an indication of stronger buoyant flows within the latter, the heat transfer mechanism is, therefore, expected to be due to convection, while conduction is responsible for the heat transfer at its low value. The temperature profiles show a feature compatible with the isotherms, i.e., a conduction-dominated heat transfer regime at low Rayleigh numbers $\left(\mathrm{Ra}<10^{5}\right)$ and a convection-dominated one with high Rayleigh numbers $\left(\mathrm{Ra} \geq 10^{5}\right)$.

The effect of the Rayleigh number on the mean Nusselt number, $\mathrm{Nu}_{\text {avg, }}$, calculated along the cavity sides is depicted in Table.1. It is noticeable that the mean transfer is an increasing function of $\mathrm{Ra}$ as the heat transfer regime becomes convection dominated.

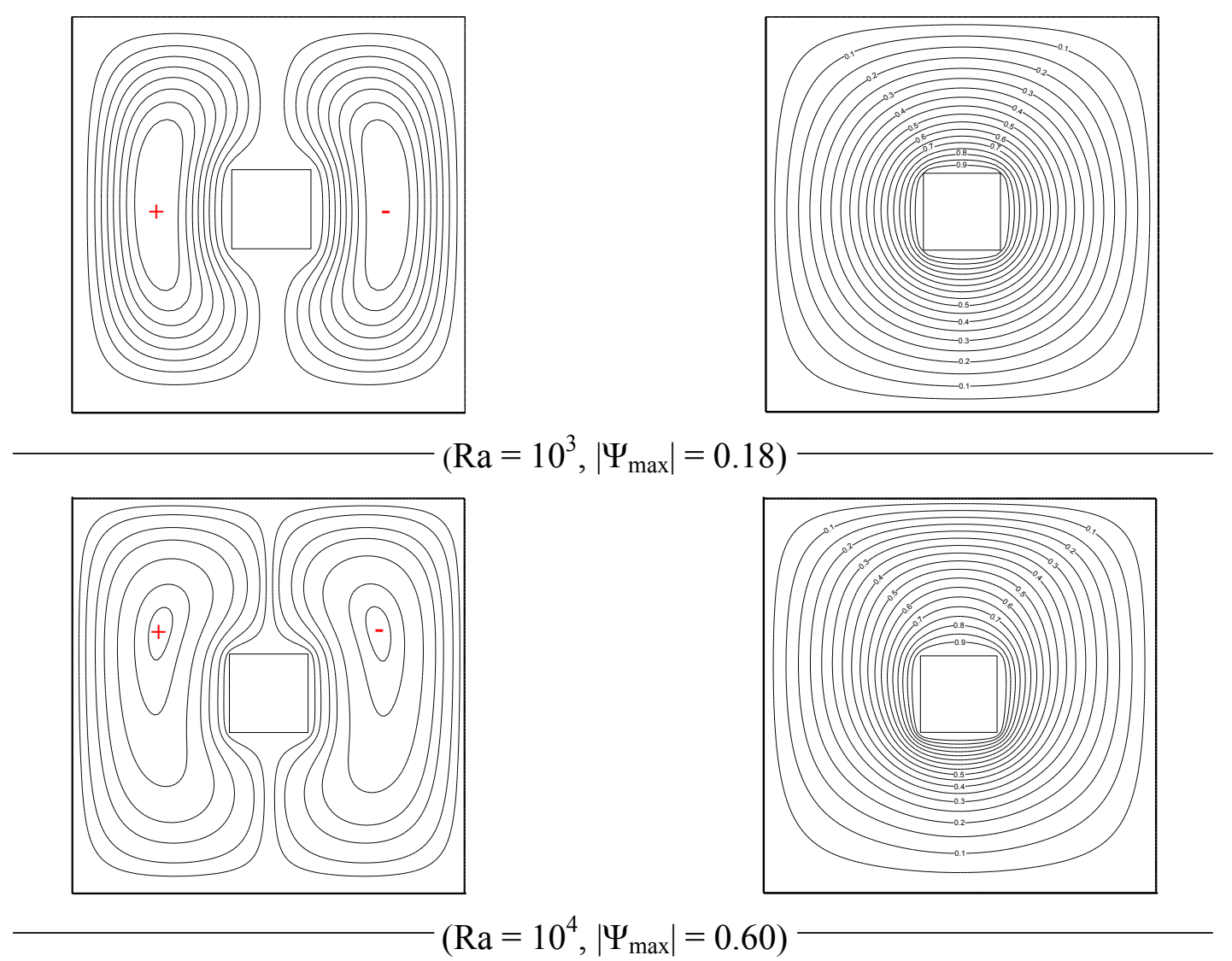



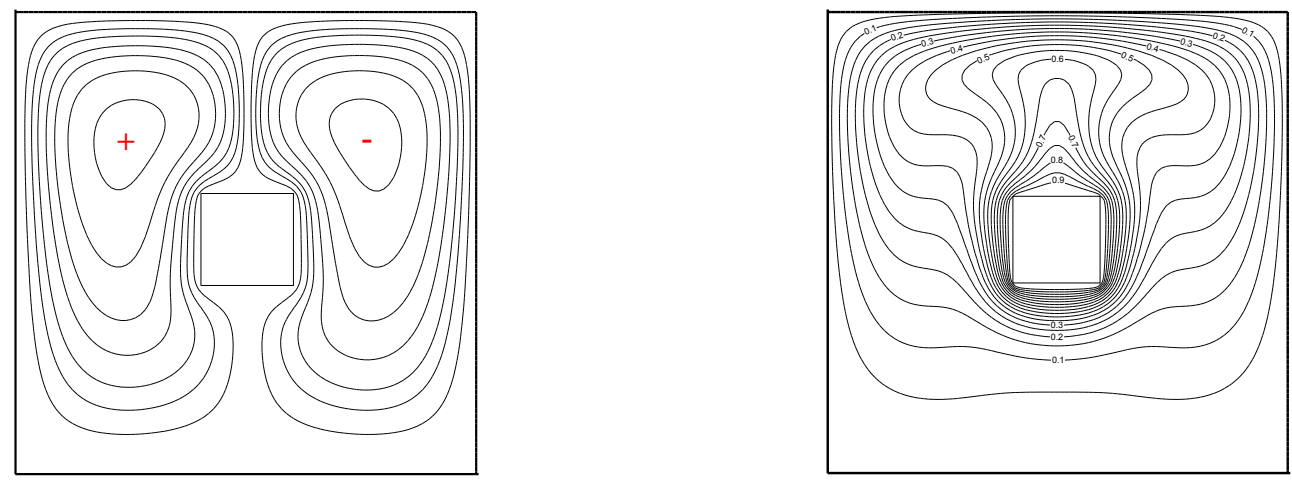

$\left(\mathrm{Ra}=10^{5},\left|\Psi_{\max }\right|=1.16\right)$
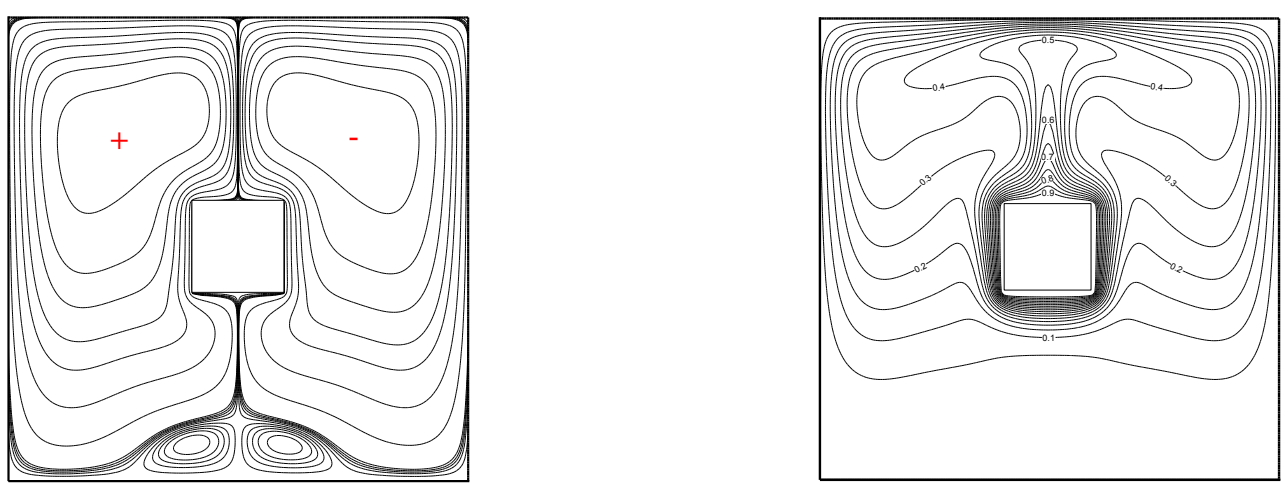

$\left(\mathrm{Ra}=10^{6},\left|\Psi_{\max }\right|=9.36\right)$

(a)

(b)

Fig. 5 Streamlines (a) and isotherms (b) in the cavity with central blockage placement (Case 1), $\operatorname{Pr}=7 ; \mathrm{w}=0.20$.
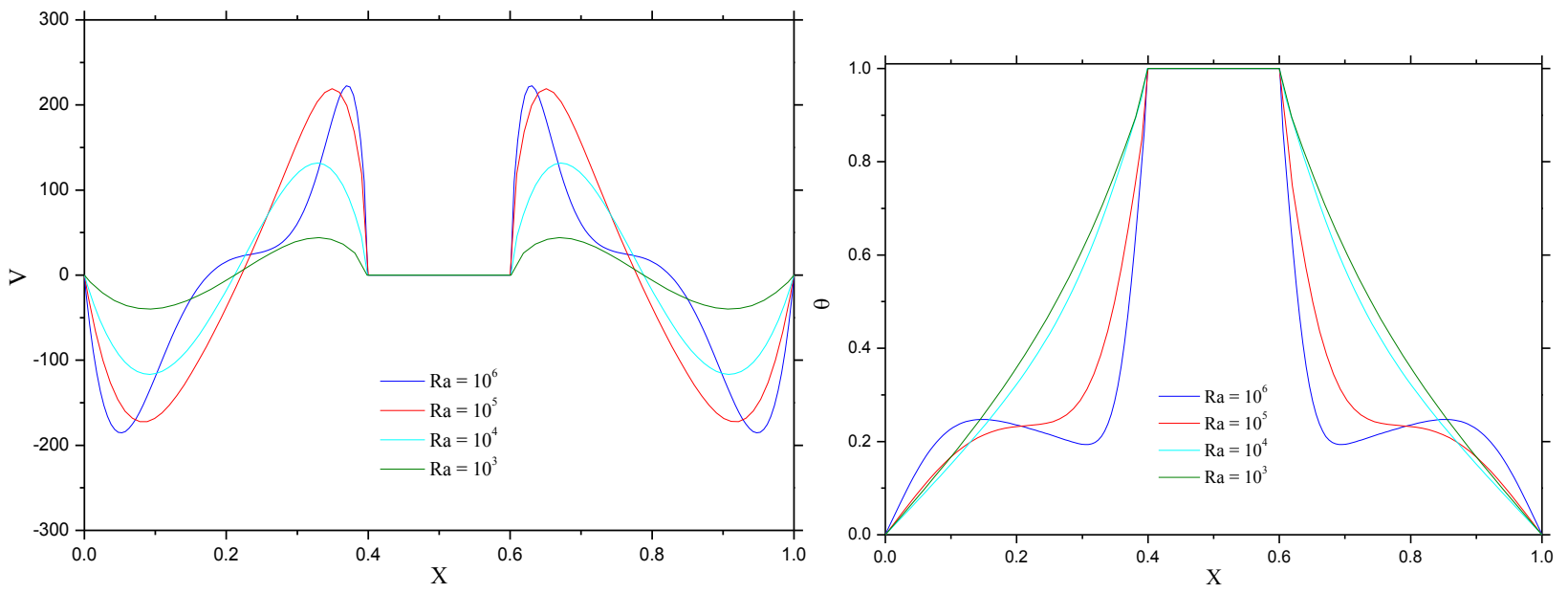

Fig. 6 Rayleigh number impact on the $\mathrm{V}$-velocity and $\theta$ profiles along the horizontal midsection of the enclosure (Case 01 ), $\operatorname{Pr}=7 ; \mathrm{w}=0.20$.

Table 1: Mean Nusselt number values according to the Rayleigh numbers.

\begin{tabular}{ccccc}
\hline $\mathrm{Ra}$ & $10^{3}$ & $10^{4}$ & $10^{5}$ & $10^{6}$ \\
\hline $\mathrm{Nu}_{\text {avg }}$ & 3.8035 & 4.1230 & 7.6843 & 11.9424 \\
\hline
\end{tabular}




\section{Heaters' Arrangement Effect}

\section{Rectangular arrangement}

Taking the second case, in which four identical heated squares (of a same total volume as the first centered heater in their summation), mounted inside the cold cavity in a rectangular arrangement as shown in Fig. 1(b). The main circulation cells as well as the isotherms are presented in Fig. 7 for three different distances (d) such as $0.20,0.40$ and 0.60 , respectively, and that for a fixed Rayleigh number taken as $10^{6}$.

Liken this case to the one before (Fig. 6), the proposed distribution does affect the flow structure of the convective fluid. For a low distance as 0.20 , two primary counter-rotating circulating cells are formed in the cavity with six secondary vortices created by the fluid motion, located at the centre of the enclosure in between the heaters, close to the bottom wall, as well as the upper one. As it can be observed, the recirculation zones located in the centre seem weak as the fluid velocity is more pronounced between the heaters.

By increasing the distance, the principal counter-rotating eddies become weaker and move to the cavity sides when the secondary vortices become stronger. Moving away from the centre of the enclosure the main vortices are found completely separated. As $d=0.60$, the heated squares get closer to the cold walls what makes the secondary vortices union with each other to form two major symmetrical vortices, thus, the primary counter-rotating eddies become quietly weak and adjacent to the side cold walls.

Summarizing the hydrodynamic behavior of the fluid into the cavity, Fig. 8 illustrates the Vvelocity profiles along the horizontal mid-plane, and that for different distances $d$. An examination of the magnitude of $\mathrm{V}$-velocity at $\mathrm{d}=0.60$ confirms the weakness of the primary rotating eddies

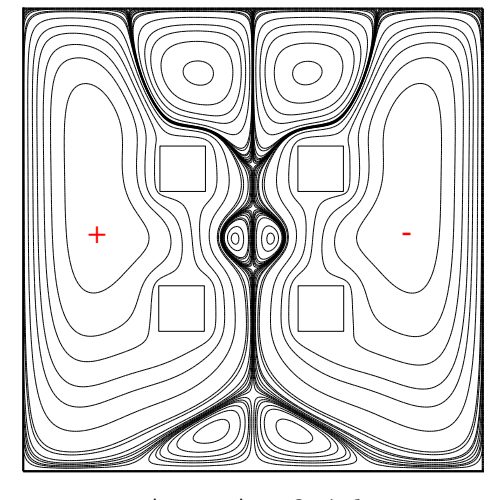

$\left|\Psi_{\max }\right|=9.16$

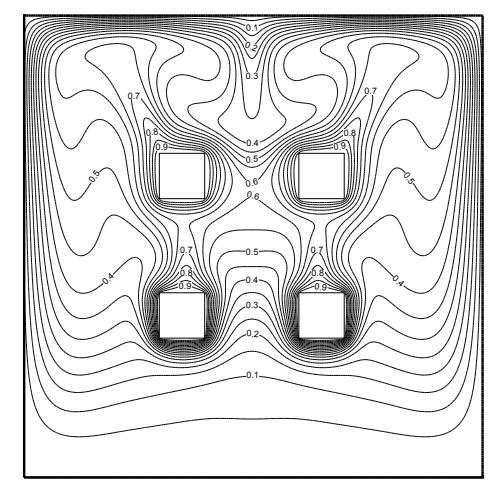

$\mathrm{d}=0.20$

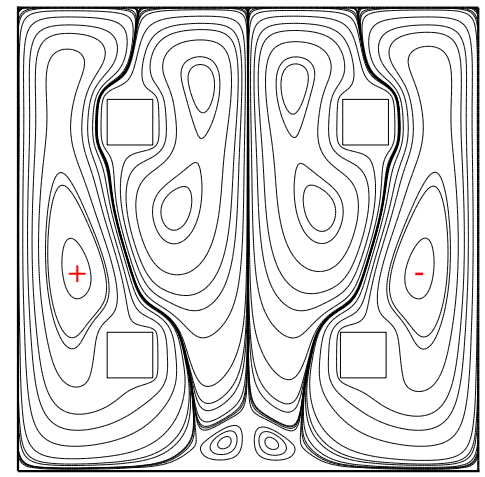

$\left|\Psi_{\max }\right|=7.87$

(a)

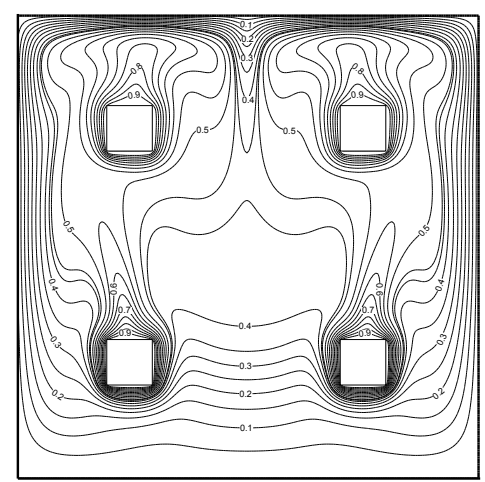

$\mathrm{d}=0.40$

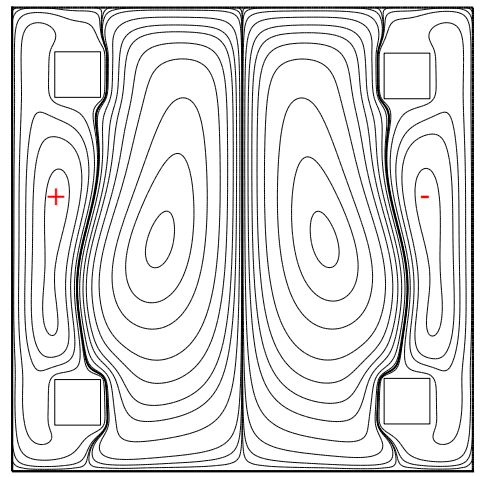

$\left|\Psi_{\max }\right|=1.55$

(b)

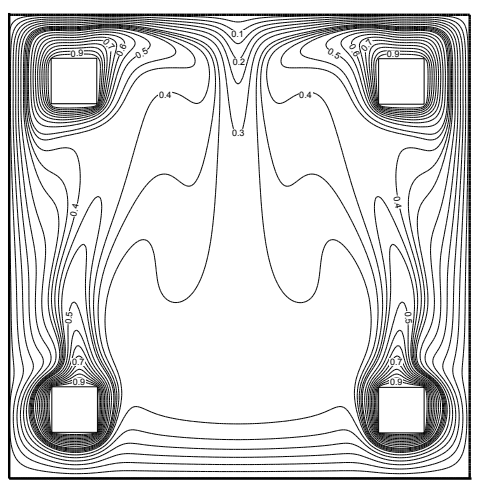

$d=0.60$

Fig. 7 Streamlines (a) and Isotherm plots (b) in the cavity with four heated squares mounted in various distances (Case 02), $\mathrm{Ra}=10^{6} ; \mathrm{Pr}=7 ; \mathrm{w}=0.10$. 


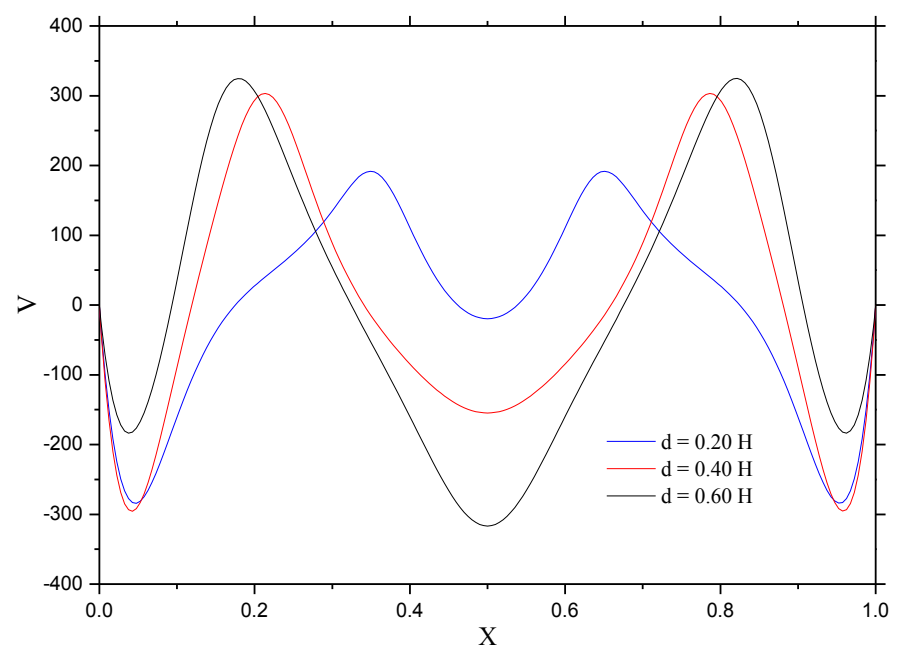

Fig. 8 V-velocity profiles along the horizontal mid-section. of the cavity for different positions

(Case 2). $\mathrm{Ra}=10^{6} ; \operatorname{Pr}=7$.

previously observed from analysing the streamlines, whereas the secondary vortices reach its maximum velocity value compared to the other distances $(\mathrm{d}=0.20$ and $\mathrm{d}=0.40)$.

In the other hand, the behavior of the corresponding isotherms is plotted in Fig. 7(b). The isotherms are clustered towards the heaters surfaces as well as along the cold vertical walls and the upper one, indicating the development of thin boundary layers over these surfaces. A further increase in the distance to 0.60 causes a raise of a thin boundary layer all along the bottom wall when the boundary layers previously observed become more intense, especially near the top corners, which will affect severely the local and the mean Nusselt numbers discussed latter.

\section{Lozenge arrangement}

As a third case, the square heaters lozenge arrangement is investigated (Fig. 1(c)). To do so, the predicted streamlines and the Isotherm plots are presented in Fig. 9. With $d=0.20$, two symmetrical counter-rotating cells are formed inside the cavity, whereas no secondary vortices is shaped compared to the previous case (Case 02). The increase in $\mathrm{d}$ over than 0.20 makes the eyes of the counter-rotating eddies move to the side walls when these ones become denser.

At 0.60 , the heated squares get closer to the cold walls and then, secondary vortices bring into being on the upper surface of the heater located close the top wall, also near its bottom surface. Fig. 10 gives a summary of the fluid behavior by presenting the V-velocity profiles along the horizontal mid-plane of the cavity. Compared to the second case, strong buoyant flow is observed near the vertical cold walls, when the absence of the secondary vortices makes the hot fluid reaches its optimum velocity value at $\mathrm{X}=0.50$.

The Isotherms for each distance $d$ are adjusted according to the presented streamlines (Fig. 9(b)). The clustering of the isotherms towards each heater surfaces, as well as along the side walls and the top one, demonstrate a higher temperature gradient with development of thin boundary layers beside these ones. It is to note that the thin boundary layer developed along the bottom wall in the case before (with $\mathrm{d}=0.60$ ) is not shaped, as only one heated square is located nearby the centre of the bottom wall what enhance the temperature gradient only at $X=0.50$. These important results will be reflected in the Nusselt numbers presented and discussed below.

\section{Nusselt number}

Figure 11 illustrates the local Nusselt number computed along each cavity wall at a fixed Rayleigh number taken as $10^{6}$ and that, for all studied cases (the first case and both; the second and the third ones at $d=0.20$ ), we get started with the right wall and following successively by the top and the bottom walls. In general, higher heat transfer is found to be when the square heaters are mounted as the second case, compared to the other ones. Concerning the $\mathrm{Nu}_{\text {upper }}$ profiles, 


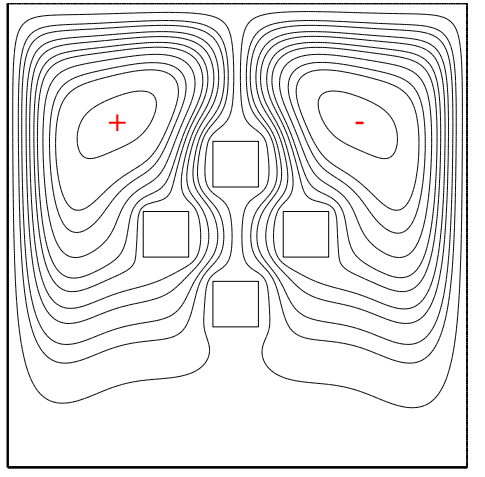

$\left|\Psi_{\max }\right|=12.18$

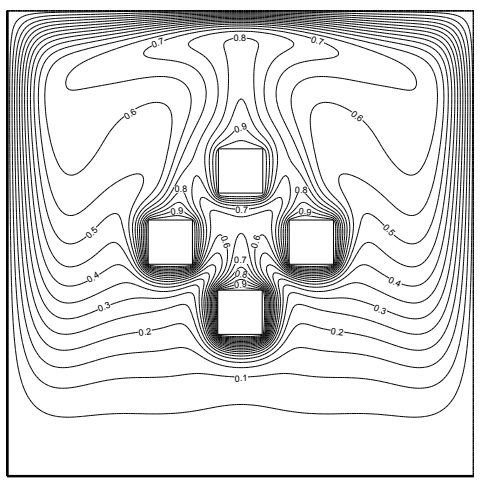

$\mathrm{d}=0.20$

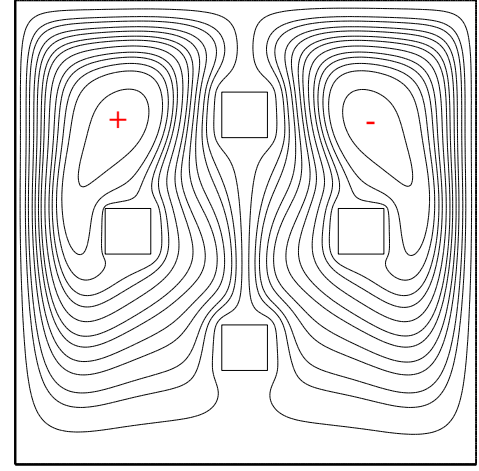

$\left|\Psi_{\max }\right|=14.66$

(a)

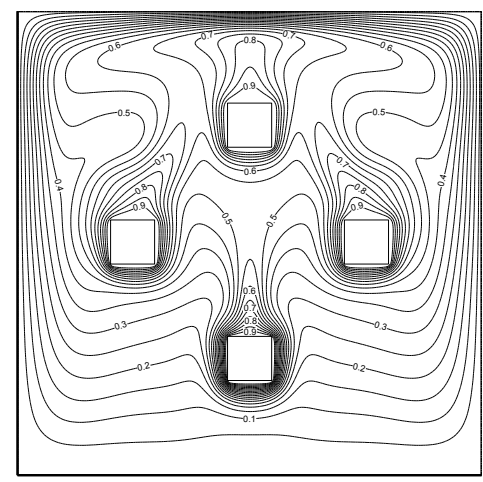

$\mathrm{d}=0.40$

(b)

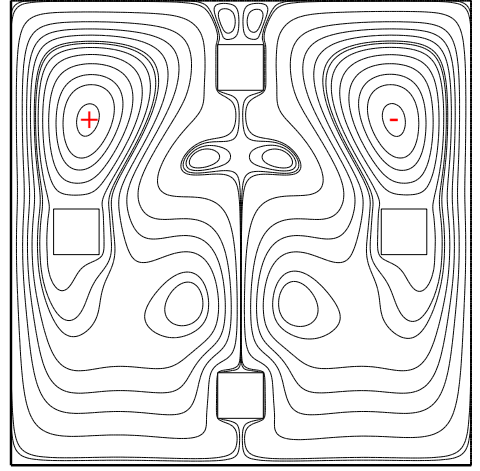

$\left|\Psi_{\max }\right|=11.21$

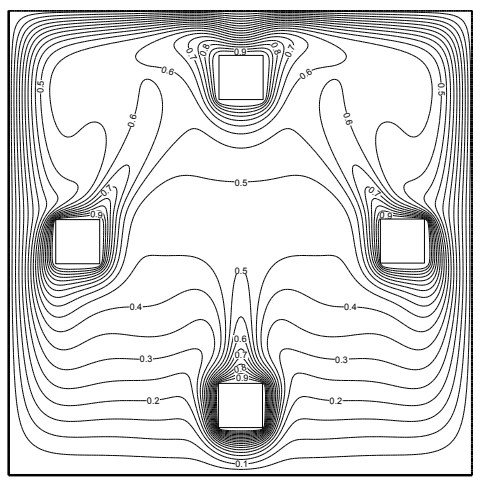

$\mathrm{d}=0.60$

Fig. 9 Streamlines (a) and Isotherm plots (b) in the cavity with four heated squares mounted in various distances (Case 03), $\mathrm{Ra}=10^{6} ; \mathrm{Pr}=7 ; \mathrm{w}=0.10$.

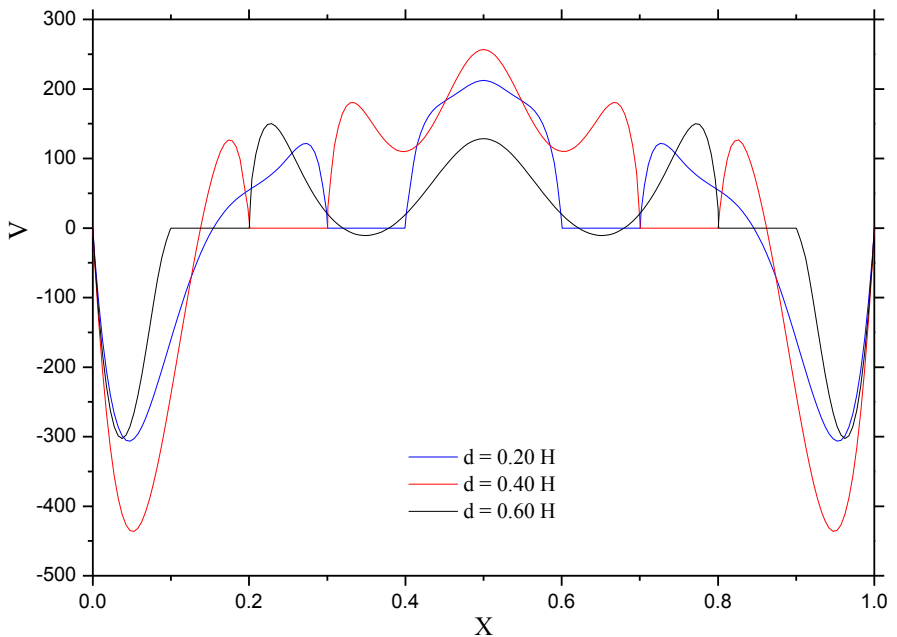

Fig. $10 \mathrm{~V}$-velocity profiles along the horizontal mid-section. of the cavity for different positions (Case 3). $\mathrm{Ra}=10^{6} ; \operatorname{Pr}=7$.

the diminution noted in Case 2 can be attributed to the earlier mentioned observation in streamlines when secondary vortices are created close to the wall what affects the temperature gradient.

Afterward, the calculated local Nusselt number of each distance is plotted in Fig. 12 for both Cases $02 \& 03$, respectively. It must be mentioned here that in case 2 , the Nubottom reaches its maximum values at $d=0.60$ compared to the other investigated distances $(0.20$ and 0.40$)$ due to the thin boundary layer presented before in the Isotherms (Fig. 7(b)). Yet, the secondary vortices 

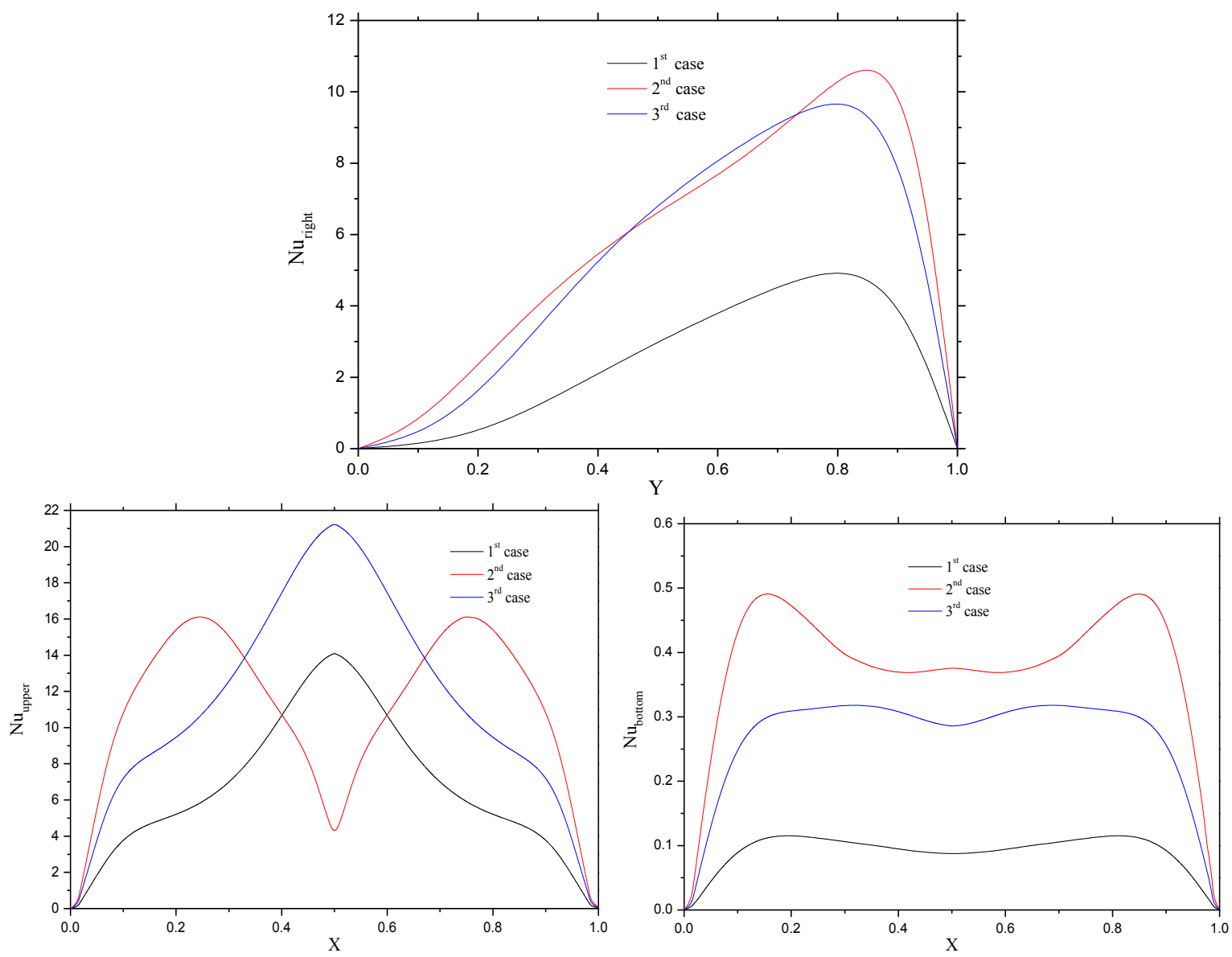

Fig. 11 Local Nusselt number evaluated at the cavity walls. Case 01: central heated square placement. Cases 02 and 03: at $\mathrm{d}=0.20 ; \mathrm{Ra}=10^{6} ; \mathrm{Pr}=7$.

affect much more the Nusselt number of the right and the top walls. In the same way, a maximum value of Nubottom is noted in the third case when $X=0.50$ due to the fact that at 0.60 , the bottom heater is so close to the cold wall.

Figure 13 illustrates the effect of different values of "d" on heat transfer enhancement inside the cavity, presented by a ratio $\mathrm{Nu}^{*}$ which can be defined as $\mathrm{Nu}_{\text {avg }}$ (Case 2 or 3)/ $\mathrm{Nu}_{\text {avg }}$ (Case 1). Summarizing the numerical results, predictive correlations relating $\mathrm{Nu}^{*}$ to the distance $\mathrm{d}$ are proposed in the form:

$$
\begin{aligned}
& \left.\mathrm{Nu}_{\text {case } 2}^{*}\right|_{\mathrm{d} \leq 0.40}=\mathrm{A}_{1} \mathrm{~d}^{2}+\mathrm{A}_{2} \mathrm{~d}+\mathrm{A}_{3} \\
& \left.\mathrm{Nu}_{\text {case } 2}^{*}\right|_{\mathrm{d} \geq 0.40}=\mathrm{A}_{4} \mathrm{~d}^{2}+\mathrm{A}_{5} \mathrm{~d}+\mathrm{A}_{6} \\
& \left.\mathrm{Nu}_{\text {case3 }}^{*}\right|_{\mathrm{d} \leq 0.40}=\mathrm{B}_{1} \mathrm{~d}+\mathrm{B}_{2} \\
& \left.\mathrm{Nu}_{\text {case } 3}^{*}\right|_{\mathrm{d} \geq 0.40}=\mathrm{B}_{3} \mathrm{~d}^{2}+\mathrm{B}_{4} \mathrm{~d}+\mathrm{B}_{5}
\end{aligned}
$$

where the coefficients of each equation are listed in Table 2 along with the $\mathrm{R}^{2}$ values to indicate the goodness of the curve-fit employed in Fig. 13. These correlations are found to predict the numerical results within $\pm 1 \%$. 

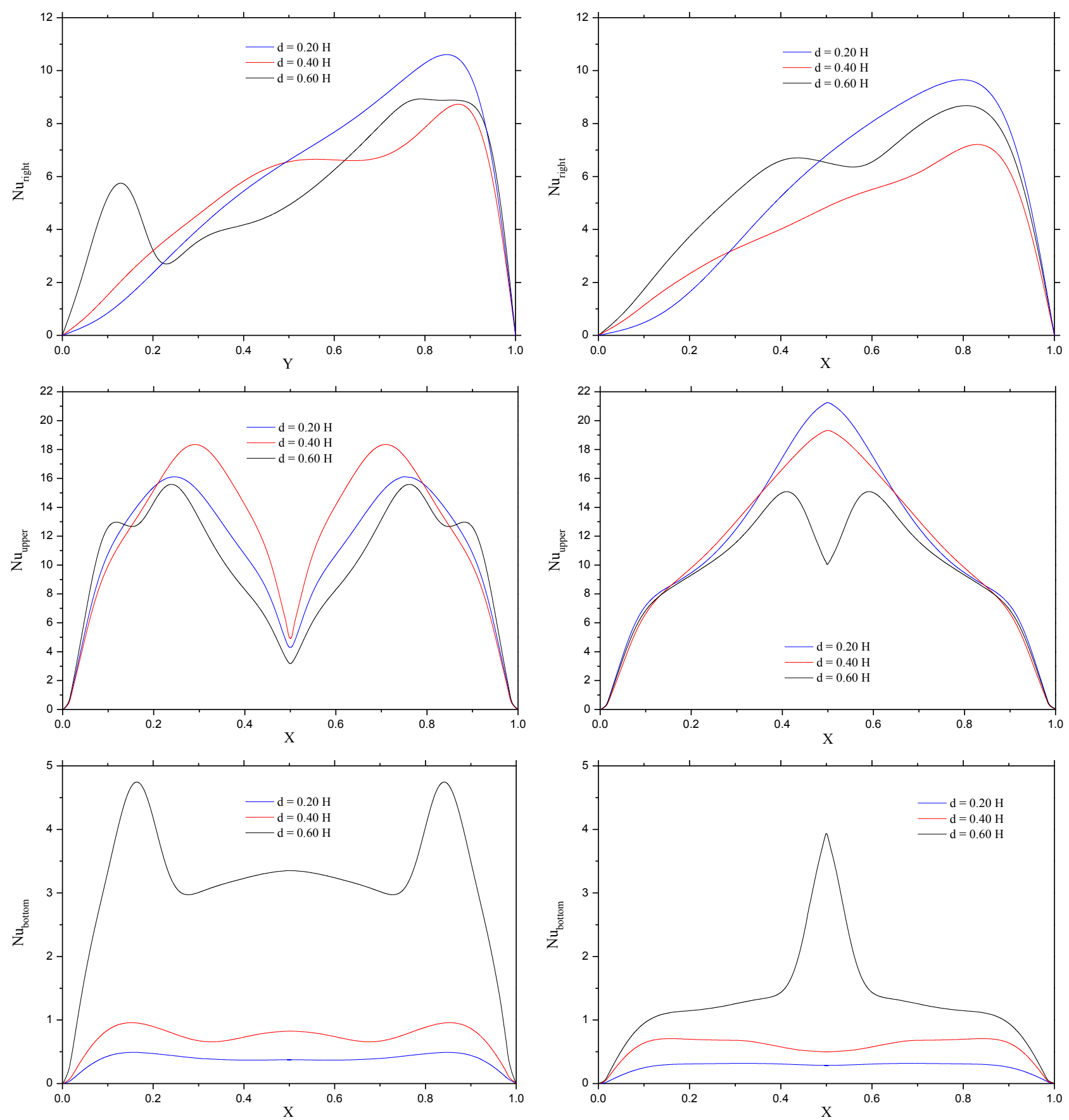

(Case 02)

(Case 03)

Fig. 12 Nusselt number evaluated at the cavity walls for both cases 02 and 03 , respectively, with different distances. $\mathrm{Ra}=10^{6} ; \operatorname{Pr}=7$.

Table 2: Values of curve-fit constants of equations $(9,10)$.

\begin{tabular}{cccccccc}
\hline $\mathrm{A}_{1}$ & $\mathrm{~A}_{2}$ & $\mathrm{~A}_{3}$ & $\mathrm{~A}_{4}$ & $\mathrm{~A}_{5}$ & $\mathrm{~A}_{6}$ & $\mathrm{R}^{2}$, Eq.9(a) & $\mathrm{R}^{2}$, Eq.9(b) \\
\hline-4.1504 & 2.7958 & 1.5123 & 3.8437 & -3.5601 & 2.7759 & 0.9978 & 0.9976 \\
\hline \hline $\mathrm{B}_{1}$ & $\mathrm{~B}_{2}$ & $\mathrm{~B}_{3}$ & $\mathrm{~B}_{4}$ & $\mathrm{~B}_{5}$ & & $\mathrm{R}^{2}$, Eq.10(a) & $\mathrm{R}^{2}$, Eq.10(b) \\
\hline-0.9802 & 2.0970 & -14.6440 & 15.4607 & -2.1476 & & 0.9980 & 0.9928 \\
\hline
\end{tabular}




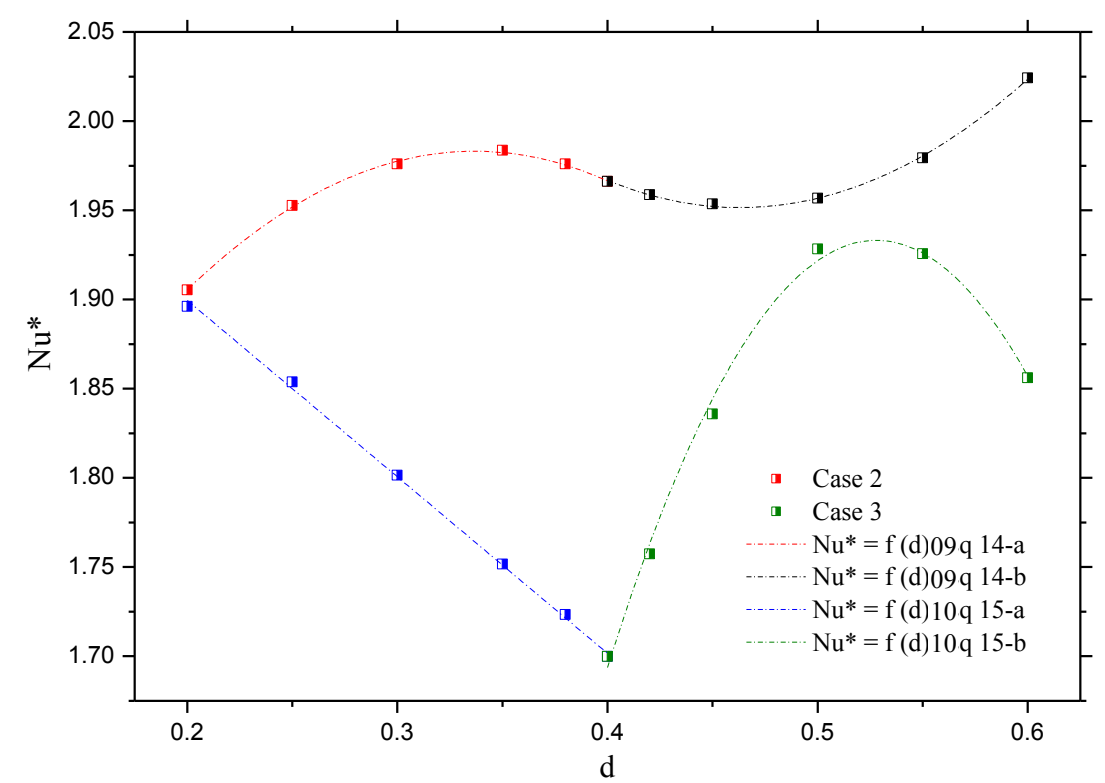

Fig. 13 Heat enhancement parameter $\mathrm{Nu}^{*}$ with $\mathrm{d}$ for both Cases $02 \& 03$. $\mathrm{Ra}=10^{6} ; \operatorname{Pr}=7$.

\section{Conclusion}

Natural convection inside a cold square cavity having an isothermally heated square block mounted in the center, or four heated squares (of a same total volume as the first centered one in their summation) mounted in a rectangular or lozenge arrangements has been studied numerically. Focused on optimal conditions for powerful heat transfer, the Rayleigh numbers as well as the proposed dispositions are critically investigated. In the case of a centered heater (Case 1), the heat transfer is found to be an increasing function of the Rayleigh number, whereas the use of square heaters (Case 2 and Case 3) is a key factor for optimal heat transfer enhancement. The rectangular arrangement of the heaters within the cold cavity is required than the lozenge one, especially when the distance " $\mathrm{d}$ " is little than 0.40 . Useful correlations predicting the heat transfer rate as a function of $\mathrm{d}$ are proposed for both cases 2 and 3, respectively, which predict within $\pm 1 \%$ the numerical results.

\section{Nomenclature}

$\mathrm{C}_{\mathrm{p}} \quad$ Specific heat transfer at constant pressure, $[\mathrm{J} / \mathrm{kg} \mathrm{K}]$

$\mathrm{d} \quad$ distance between the heaters, $[\mathrm{m}]$

Gr Grashof number, $\left(=g \beta \rho^{2} \Delta T H^{3} / \mu^{2}\right)$

$\mathrm{H}$ Cavity height, [m]

$\mathrm{k}$ Thermal conductivity, [W/m K]

$\mathrm{Nu} \quad$ Nusselt number

$\mathrm{p}$ Pressure, $[\mathrm{Pa}]$

$\mathrm{P} \quad$ Dimensionless pressure

Pr Prandtl number, $\left(=C_{p} \mu / k\right)$

Ra Rayleigh number, $\left(=g \beta \rho^{2} \Delta T H^{3} C_{p} / \mu k\right)$

$\mathrm{T} \quad$ Dimensional temperature, $[\mathrm{K}]$

$\mathrm{u}, \mathrm{v}$ Dimensional velocity components in $\mathrm{x}$ and y direction, $[\mathrm{m} / \mathrm{s}]$

U, V Horizontal and vertical dimensionless

\begin{tabular}{ll}
\multicolumn{3}{c}{ velocity components } \\
W & Partition width, $[\mathrm{m}]$ \\
$\mathrm{X}, \mathrm{y}$ & Cartesian coordinates, $[\mathrm{m}]$ \\
X, Y & Dimensionless Cartesian coordinates \\
Greek & letters \\
$\beta$ & Thermal expansion coefficient, $[1 / \mathrm{K}]$ \\
$\theta$ & Dimensionless temperature \\
$\mu$ & Plastic viscosity, $[\mathrm{kg} / \mathrm{m} \mathrm{s}]$ \\
$\rho$ & Fluid density, $\left[\mathrm{kg} / \mathrm{m}^{3}\right]$ \\
$\Psi$ & Stream function \\
Subscript \\
$*$ & Ratio \\
avg & Average \\
$\mathrm{c}$ & Cold \\
$\mathrm{h}$ & Hot
\end{tabular}




\section{References}

[1] K.E. Torrance, L. Orloff, J.A. Rocket, Experiments on natural convection in enclosures with localized heating from below, J. Fluid Mech. 36 (1969) 21-31.

[2] G. De Vahl Davis, Natural convection of air in a square cavity: a benchmark numerical solution, Int. J. Num. Meth. Fluids 03 (1983) 249-264.

[3] G. Barakos, E. Mitsoulis, Natural convection flow in a square cavity revisited: laminar and turbulent models with wall functions, Int. J. Nume. Meth Fluids 18 (1994) 695-719.

[4] K.T. Yang, Natural convection in enclosures, Handbook of Single Phase Convection Heat Transfer, Wiley, New York (1987).

[5] F. Corvaro, M. Paroncini, An experimental study of natural convection in a differentially heated cavity through a 2D-PIV system, Int. J. Heat Mass Transf. 52 (2009) 355-365.

[6] P. Bhave, A. Narasimhan, D.A.S. Rees, Natural convection heat transfer enhancement using adiabatic block: optimal block size and Prandtl number effect, Int. J. Heat Mass Transf. 49 (2006) 07-18.

[7] J.R. Lee, M.Y. Ha, Numerical simulation of natural convection in a horizontal enclosure with a heat generating conducting body, Int. J. Heat Mass Transf. 49 (2006) 2684-2702.

[8] H.F. Oztop, E. Bilgen, Natural convection in differentially heated and partially divided square cavities with internal heat generation, Int. J. Heat Fluid Flow 27 (2006) 466-475.

[9] A. Abdallah, K. Khalil, P. Ioan, Buoyancy-induced flow and heat transfer in a partially divided square enclosure, Int. J. Heat Mass Transf. 52 (2009) 3818-3828.

[10] O. Laguerre, S. Benamara, D. Remy, D. Flick, Experimental and numerical study of heat and moisture transfer by natural convection in a cavity filled with solid obstacles, Int. J. Heat Mass Transf. 52 (2009) 5691-5700.

[11] S. Hua, C. Eric, L. Guy, Effect of surface radiation on the breakdown of steady natural convection flows in a square air-filled cavity containing a centered inner body, Appl. Ther. Eng. 31 (2011) 1252-1262.

[12] K.S. Mushatet, Simulation of laminar natural convection in a cavity with cylindrical obstacles. Aust. J. Basic Appl. Sci. 05 (2011) 636-645.

[13] K. Ragui, Natural convection heat transfer in a differentially heated enclosure with adiabatic partitions and filled with a Bingham fluid, Heat Transf. Res. 46 (08) (2015) 765-783.

[14] M. Bouafia, O. Daube, Natural convection for large temperature gradients around a square solid body within a rectangular cavity, Int. J. Heat Mass Transf. 50 (2007) 3599-3615.

[15] M.Y. Ha, M.J. Jung, A numerical study on three-dimensional conjugate heat transfer of natural convection and conduction in a differentially heated cubic enclosure with a heatgenerating cubic conducting body. Int. J. Heat Mass Transf. 43 (2000) 4229-4248.

[16] I. Dagtekin, H.F. Oztop, Natural convection heat transfer by heated partitions within enclosure, Int. Commun. Heat Mass Transf. 40 (2001) 823-834.

[17] F. Ampofo, Turbulent natural convection of air in a non-partitioned or partitioned cavity with differentially heated vertical and conducting horizontal walls, Exper. Thermal Fluid Sci. 29 (2005) 137-157.

[18] A. Amine, J.K. Platten, M. Hasnaoui, Thermal convection around obstacles: the case of Sierpinski carpets, Exp. Fluids 36 (2004) 717-727.

[19] A. Raji, M. Hasnaoui, M. Naïmi, K. Slimani, M.T. Ouazzani, Effect of the subdivision of an obstacle on the natural convection heat transfer in a square cavity, Comp. Fluids 68 (2012) 0115 . 
[20].T. Zhang, D. Che, Double MRT thermal lattice Boltzmann simulation for MHD naturalconvection of nanofluids in an inclined cavity with four square heat sources, Int. J. Heat Mass Transf. 94 (2016) 87-100.

[21] A. Bejan, Convection heat transfer, John Wiley and Sons. Inc. Hoboken, New jersey (2004).

[22] S.V. Patankar, Numerical heat transfer and fluid flow, Mc Grow, New York (1980).

[23] O. Turan, N. Chakraborty, R.J. Pool, Laminar natural convection of Bingham fluid in a square enclosure with differentially heater side walls, J. Non-Newt. Fluid Mech. 165 (2010) 901-913.

[24] B. Calcagni, F. Marsili, M. Paroncini, Natural convective heat transfer in square enclosure heated from below, Appl. Thermal Eng. 25 (2005) 2522-2531.

[25] G.V. Kuznetsov, M.A. Sheremet, Numerical simulation of turbulent natural convection in a rectangular enclosure having finite thickness walls, Int. J. Heat Mass Transf. 53 (2010) 163177. 